
3 Research Square
Preprints are preliminary reports that have not undergone peer review.
They should not be considered conclusive, used to inform clinical practice, or referenced by the media as validated information.

\title{
The experiences and attitudes among Chinese soft tissue sarcoma patients: a qualitative study using expressive writing
}

\author{
Nan Lin \\ West China Hospital \\ Yaotiao Deng \\ Sichuan University \\ Weige Wei \\ West China Hosptial \\ Taolin Qin \\ West China Hosptial \\ Yu Jiang ( $\sim$ jiang_yu@scu.edu.cn ) \\ Sichuan University
}

\section{Clinical trial}

Keywords: soft tissue sarcoma, expressive writing, qualitative study, psychological status

Posted Date: March 1st, 2022

DOI: https://doi.org/10.21203/rs.3.rs-1374788/v1

License: (a) (i) This work is licensed under a Creative Commons Attribution 4.0 International License. Read Full License 


\section{Abstract}

Purpose

With poor diagnose and limited knowledge, soft tissue sarcoma (STS) patients were affected by their suffering. Chinese STS patients are often not willing to talk about their feelings and thoughts publicly, which may have negative impact on their psychological status. Expressive writing allows people to disclose their thoughts during writing, which has not yet been studied in patients with soft tissue sarcoma. This study was conducted to understand the experience and attitude of Chinese STS patients using expressive writing.

Method

Seven participants with soft tissue sarcoma were included to take 6 episodes of expressive writing with structured guidance. Standard qualitative research method was used to analyze the writing materials.

Result

Four themes were identified: treatment process, interpersonal relationship, coping strategies, views about the future. We depicted some crucial aspects of life for STS patients in China, that they may have many difficulties and struggles, but most of them still face life with a positive attitude.

Conclusion

Expressive writing was acceptable and feasible in Chinese STS patients. We revealed the dynamic process of acceptance and adaptation to life change in them. Itis necessary for doctors and nurses to understand the specific psychological status of STS patients in order to improve their quality of life.

Trial registration: ChiCTR2000038923

\section{Introduction}

Soft tissue sarcoma (STS) represents a rare group of malignancies rising from mesenchymal tissue and it accounts for only $1 \%$ of all adult malignancies[1]. The diagnosis and the treatment process can be complex and challenging because of its heterogeneous nature and the patients' limited knowledge[2]. With advances in personalized therapy and increasing survival rates, the treatment of STS is becoming more focused on the quality of life and psychological rehabilitation[3, 4]. It is necessary and beneficial for patients to have interpersonal communication with others like family, friends and health caregivers[5, 6]. Some STS patients may seek psychosocial support from family and friends in practical, physical, emotional and financial aspects, some of whom can play an important role in the process when patients re-accepting their new identity and restarting their new journey of life[7, 8].

However, cancer-related topics are poorly discussed in STS patients in China. Chinese cancer patients are usually not willing to talk about their feelings publicly, especially regarding the topic of death[9]. They don't want to share their true feelings because they are reluctant to burden their family or friends, and they want to act like the normal during their routine relationships[10]. Our previous study found that Chinese families were likely to let the cancer patients know less about their disease, while nearly half of patients (47.9\%) believed that they should be informed of cancer diagnosis before their families $[11,12]$. Therefore, the barriers of self-expression and interpersonal communication, as well as this conjecture and the scare of uncertain diagnosis may have negative impacts on their psychological condition and may cause a lack of understanding between the doctors and the patients.[12].

Expressive writing is a psychological intervention invented by Pennebaker, which allows people to disclose their thoughts and beliefs during writing[13]. The process of writing about their deepest thoughts and feelings may help convert disorganized emotions into organized thoughts. Participants can recall and reorganize their illness experience in a relaxed environment, and they may develop a coherent narrative of their experience, attitude and eventually benefit from their experience[14]. Previous studies have explored expressive writing in some types of cancer. One study found that expressive writing may reduce cancer-related symptoms and improve physical functioning in renal cell carcinoma patients[15]. Other studies also demonstrated that the quality of life of breast cancer and colorectal survivors were improved after expressive writing[16, 17]. However, no similar study was conducted in STS patients. For patients with a rarely known cancer, they may have unique experience which are different from other types of cancer patients. In this study, we investigated the experience and attitude of STS patients during treatment through their expressive writing, and we undertook a qualitative analysis of their narratives.

\section{Methods}

\subsection{The Current Study}

Patients were randomly assigned to expressive writing group, cancer fact group, and neutral writing group. In this part, we chose a qualitative research method to analyze the narratives in the expressive group and explored the experience and attitude of Chinese STS patients. Primarily we wanted to analyze the feasibility of expressive writing. In the second part, we will compare the physical and psychological effect of three types of writing in STS patients.

\subsection{Participants}


The inclusion criteria were as follows: (I) a stage I to IV diagnosis of STS, (II) over 18 years of age, (III) more than 3 months from initial diagnosis, (IV) able to write Chinese and willing to express their emotions, and (V) ability to complete the follow-up research. The exclusion criteria were: (I) couldn't stand long time of writing, (II) had a history of mental illness, and (III) underwent other psychotherapy or psychotropic medications. Ethical approval was obtained from the Research Ethics Committee on Biomedical Research, West China Hospital of Sichuan University (No. 2020-557). The research was registered in the Chinese Clinical Trial Registry (ChiCTR) with registration number ChiCTR2000038923.

\subsection{Procedure}

All participants fulfilling the inclusion criteria were asked if they were willing to write their stories and feelings. Written informed consent and baseline assessment were obtained from patients when they agreed to participant this study. Then participants were told to share their experiences and feelings where they felt comfortable and convenient, then sent back their writings via e-mail. They were asked to write once a week for six times, each writing was guided with instructions. The major topic of each writing was: the things had bothered them recently and their solution (week 1 ), the most impressive person during the illness (week 2), their emotional changes during diagnosis (week 3), their efforts made in the fight against cancer (week 4), their gain from the experience of cancer (week 5), and their view on the future (week 6).

\subsection{Data analysis}

We used a qualitative research method to analyze the writing materials[18]. The detailed procedure was as follows: (1) the participants' writing materials were interpreted into word documents from Chinese to English. (2) All essays were read and identified to figure out the meaningful units. (3) All meaningful units were reviewed and compared, and then discussed by the authors. (4) The themes and subthemes were generated after discussion. Any divergences would be discussed among the authors until we got a consensus.

\section{Results}

We finally included 7 participants in this study. The detailed demographic characteristics of the participants were listed in Table 1. After data analysis, we identified 4 themes and 10 subthemes, Table 2 provided a summary of the themes and subthemes identified in this study. Each theme presented different aspects of feelings and experience in patients, but it was intrinsically connected to each other. Findings were supported by quotes in their writing materials, which presented the experience and attitude for each patient.

Table 1

Characteristics of the participants $(n=7)$

\begin{tabular}{|c|c|c|c|c|c|c|c|c|c|c|}
\hline No. & Age(years) & Gender & Marital & Occupation & Education & Religion & Diagnosis & $\begin{array}{l}\text { Time } \\
\text { since } \\
\text { diagnosis } \\
\text { (months) }\end{array}$ & Stage & Treatments \\
\hline A & 32 & Man & Married & $\begin{array}{l}\text { Part-time } \\
\text { job }\end{array}$ & $\begin{array}{l}\text { Bachelor } \\
\text { degree or } \\
\text { above }\end{array}$ & Absence & Synovial sarcoma & 12 & प & $\begin{array}{l}\text { Sugery, } \\
\text { chemotherapy } \\
\text { and } \\
\text { radiotherapy }\end{array}$ \\
\hline B & 22 & Woman & Married & Unemployed & $\begin{array}{l}\text { Below } \\
\text { bachelor } \\
\text { degree }\end{array}$ & Absence & Ewing's sarcoma & 10 & प & $\begin{array}{l}\text { Sugery, } \\
\text { chemotherapy } \\
\text { and } \\
\text { radiotherapy }\end{array}$ \\
\hline $\mathrm{C}$ & 19 & Man & Unmarried & Unemployed & $\begin{array}{l}\text { Below } \\
\text { bachelor } \\
\text { degree }\end{array}$ & Presence & Rhabdomyosarcoma & 8 & प & $\begin{array}{l}\text { Sugery, } \\
\text { chemotherapy } \\
\text { and } \\
\text { radiotherapy }\end{array}$ \\
\hline D & 50 & Woman & Married & Full-time job & $\begin{array}{l}\text { Bachelor } \\
\text { degree or } \\
\text { above }\end{array}$ & Absence & Leiomyosarcoma & 5 & प & $\begin{array}{l}\text { Targeted } \\
\text { therapy }\end{array}$ \\
\hline$E$ & 30 & Woman & Married & Unemployed & $\begin{array}{l}\text { Below } \\
\text { bachelor } \\
\text { degree }\end{array}$ & Absence & Rhabdomyosarcoma & 7 & प & $\begin{array}{l}\text { Chemotherapy } \\
\text { and } \\
\text { radiotherapy }\end{array}$ \\
\hline $\mathrm{F}$ & 43 & Woman & Married & $\begin{array}{l}\text { On sick } \\
\text { leave }\end{array}$ & $\begin{array}{l}\text { Bachelor } \\
\text { degree or } \\
\text { above }\end{array}$ & Absence & Rhabdomyosarcoma & 11 & प & $\begin{array}{l}\text { Sugery and } \\
\text { chemotherapy }\end{array}$ \\
\hline G & 51 & Man & Married & Full-time job & $\begin{array}{l}\text { Bachelor } \\
\text { degree or } \\
\text { above }\end{array}$ & Absence & Rhabdomyosarcoma & 17 & [ & $\begin{array}{l}\text { Sugery, } \\
\text { chemotherapy } \\
\text { and } \\
\text { radiotherapy }\end{array}$ \\
\hline
\end{tabular}


Table 2

Summary of themes and subthemes

\begin{tabular}{|ll|}
\hline Themes & Subthemes \\
\hline Treatment process & Happiness and disappointment when misdiagnosed as benign \\
\hline & Confusion and sadness when diagnosed \\
\hline Interpersonal relationship & Gistressed about the side effects of treatment \\
\hline Coping strategies & Support and fear from cancer peers \\
\hline & Multiple consultation on treatment options \\
\hline Views about the future & Loss and appreciation of their jobs \\
\hline & Dealing with negative emotions \\
\hline & Expectations about the future \\
\hline
\end{tabular}

\subsection{Treatment process}

\subsubsection{Happiness and disappointment when misdiagnosed as benign}

Some patients could be misdiagnosed as benign at the beginning. Under such condition, the patients and their family could be excited at that time.

Participant A: The first time the result came out, the doctor said that it might be benign. At that time, I felt relaxed, and my wife was so excited that she cried.

However, they felt disappointed and angry when looking back to their misdiagnosis. The experience of misdiagnosis delayed the correct diagnosis process and may result in the progression of the patients' disease. Some patients put blame on the initial clinician, which may cause their lack of trust in medical professionals.

Participant G: I was hospitalized in a local hospital and underwent a series of examinations. The pathology was benign and the doctor said it could be treated conservatively. However, my symptoms began to get worse afterwards. I didn't know if this was my sorrow or the sorrow of medicine, because this "benign" tumor almost killed my life.

\subsubsection{Confusion and sadness when diagnosed}

When diagnosed, most of the patients felt confused and helpless because of the poor prognosis and disruption of normal life. They felt they were not able to continue their life as it used to be even though some were very young.

Patient C: Last August I was diagnosed with sarcoma, which meant that my body was not as healthy as I had imagined and my dreams were shattered. Since the childhood, I had been looking forward to take on the mission of protecting my country. However, my lifelong dream was over.

\subsubsection{Distressed about the side effects of treatment}

All patients in this study underwent chemotherapy or targeted therapy, and they recorded their side effects of the treatment such as nausea, hair loss, fatigue, taste alteration, leukopenia, etc. Most of them would overcome the side effects by themselves when the symptoms were still mild to moderate. But when the side effects were so strong that the patients couldn't continue their treatment, they tended to seek help from others or even stop the medicine.

Patient B: Today is my first day of discharge. I got up and then threw up in the morning. I also felt a little bitterness in my mouth, so I had a cup of tea. After coming home last night, my head hurts a bit, and it was still the same now. I hope it would be fine in a few days.

For some patients, they attached more importance to their quality of life and want to experience less side effects, so their treatment options were also affected.

Patient D: I chose the targeted therapy with the least side effects, but I still felt uncomfortable. First of all, the wound has not healed after taking the drug, and I had to clear the wound every two days, which made me painful. Even worse, it split again and again. Later, the drug was stopped, and the side effects finally left me, which made me comfortable again.

3.2 Interpersonal relationship

\subsubsection{Gratitude and stress from the family}


Because of the disease, patients felt their ties with their loved ones became closer. All patients in our study recorded how their family support them and expressed their gratitude to their family.

Patient C: During this illness, I suddenly found that my parents, relatives and friends were so united. Some of them took care of me by my side, some came from their hometown hundreds of kilometers away, some used their social relationships to help me find a specialist, and some often recite the scriptures and pray for me. All these made me feel infinite sense of security.

The treatment process of STS could last for a long time, some patients felt guilty and stressed about their illness.

Patient E: The results of the examination are not satisfying, and I am worried that I couldn't afford to change the treatment plan later. My illness brought too much trouble to my family's lives, especially my sister's. In order to take care of me, she hasn't gone to work since I was sick, I really hope to end this journey soon.

\subsubsection{Support and fear from cancer peers}

For most STS patients, they hadn't heard about the disease before their diagnosis. They felt lack of the medical information and some patients tended to seek support from their cancer peers. They support each other emotionally and materially.

Patient C: He was a boy with dark skin, who was two years older than me. We became good friends and encouraged each other. During my third cycle of chemotherapy, he told me that he would like to bring me some gifts from his hometown next time. But then tragedy struck suddenly. He failed to fight against cancer after all. I felt into a trance and started to worry about everything.

\subsection{Coping strategies}

\subsubsection{Multiple consultations on treatment options}

When faced with the problems of treatment decision, most of the patients tended to seek advice from those close to them, especially from their families, and take all aspects into consideration.

Patient D: I asked my doctor how to treat the cancer and I came to know chemotherapy and targeted therapy. My family, relatives and friends were not in favor of chemotherapy, so I decided to do targeted therapy after careful consideration.

In China, family are usually involved in the decision-making process, but some patients thought their family were so close that their emotion are easy to be affected by family members when the disease progressed or relieved, so they seek their friends for help.

Patient F: The treatment cannot go on without my family's support, but I was also afraid that my family's normal lives would be affected. Should I tell them everything, or just provide the necessities? But I do often discuss my condition with my friends. We are in the same condition, we can discuss the disease in detail, and we can also talk about the treatment choices.

\subsubsection{Loss and appreciation of their jobs}

Most of the STS patients had to give up their jobs and reorientate their own social functions. Some patients felt disappointed about the change and maladjusted, and they still wanted to restart their jobs, but they finally adapted life without work.

Patient A: As a previous entrepreneur, I was under pressure. At many times, I wanted to cry because no one had ever shared the hardship with me. I never took a vacation until I was sick and hospitalized! During this year in hospital, I did not take over any of the company's affairs. Although I was not satisfied with what they did, I tried to be less concerned about it. Maybe life is more important than career!

Some patients continued working during treatment. While continuing to work, they made money and received care from colleagues, and their psychological condition improved.

Patient F: The last two weeks had been the best time since I was sick. I went to work, ate out with friends, and play with my children. I felt completely like a normal person. I enjoyed myself this time and I really felt the resurgence of my life.

\subsubsection{Dealing with negative emotions}

During therapy, patients had to face a lot of negative emotions. Some of them just endure silently until these emotions were gradually receded. And some patients summarized some methods to cope them.

Patient G: I do need a long time to deal with my negative emotions and I have summarized some methods. One is to correctly understand cancer and treatment, and to look at life relatively calmly. The second is to develop hobbies. The third is to do something for my daughter's business. This is one of the motivations for me to socialize during radiotherapy and chemotherapy.

\subsection{Views about the future}

\subsubsection{Fear about the future}


With the life-threatening diagnosis of STS, most patients felt uncertain about the future. Their worries were complex, not just for themselves, but also for their family and friends. They were truly scared about the recurrence, death and associated feelings of anxiety and fear, but they had to face it.

Patient G: I slowly calmed down and began to recognize the reality that I have a terminal illness. Firstly, I must admit that I have suffered from cancer, and unfortunately, there may be no future. Secondly, some of my dreams haven't been achieved yet, I need to use the last time to make my life less regrettable, the thing I fear most is no longer the loss of my life itself, but the process.

Most of them also feared for their family. They worried about what may happen if they left their loved ones someday because they couldn't support their families anymore.

Patient A: I cannot imagine what would happen to my family if I were not there. I am afraid that they will be bullied and hurt because of my absence. I will do everything I can to let myself overcome the illness, even if I don't have any superpowers.

\subsubsection{Expectations about the future}

Even experiencing so much struggle and pain, most patients were still hopeful about their future. They prepared for the best and the worst, and some patients hope their disease could be cured.

Patient E: I know that cancer will recur. I am worried that in the future, my family will be dragged down on my road of fighting cancer. If possible, I hope to support my parents after their retirement. If possible, I hope to watch my sister get married and have children. If possible, I hope to accompany my son to grow up and watch him to settled. If possible, I hope to accompany my lover for the entire life.

Most patients mentioned they want their life back to the normal in the future if they were cured, and restart a new journey. Their expectations for the future were simple and their families were always considered in their future plans.

Patient G: In fact, I have been working hard for many things I dreamed for a long time. If my situation turns good, everything will return normal, and I will start a brand-new journey. Maybe I will get another car to enjoy the beautiful landscapes of my motherland.

Some of the patients hope to do something useful for the society like volunteering.

Patient B: I also want to work in a nursing home and cook for the elder. I always feel that the food in the nursing home is not hygienic and the elder are very lonely. I can chat with them and dance with them, so they should be better off.

\section{Discussion}

Previous qualitative studies predominantly used face-to-face interviews to understand the experience, needs and hopes among STS patients[19, 20]. As Asian cultures often value collectivism and proper display of emotions, it may be difficult for face-to-face interviews to elicit personal expression[21]. In this context, expressive writing is more brief and provides more flexible time, space and privacy for the patients to express themselves freely. During expressive writing, participants reorganized their experience and feelings, hence allowed patients to disclose their private thoughts[22, 23]. However, conventional expressive writing didn't have a specific guide, participants' narration of their illness experiences was usually causal and it was difficult to explore deeper emotions and topics [24], so we conducted this invention with longer writing sessions (6 compared with normally 4 sessions) and more detailed writing guidance to solve the problems in previous research. By analyzing the writing materials, we found four meaningful themes: treatment process, interpersonal relationship, coping strategies, views about the future.

This study primarily observed how STS patients reacted the first time when diagnosed as benign. Compared with other types of cancer, the diagnosis of soft tissue sarcoma may be more tortuous[25,26]. The reasons why STS patients experienced delayed diagnose and misdiagnose were reported as the atypical symptoms, the complexity of pathological types, inexperience of the primary care physician and the inappropriate test for diagnose[27-29]. The experience of being misdiagnosed could cause severe emotional swings included temporary happiness and prolonged depress. Moreover, we also found that misdiagnosis may cause the patient's distrust of the doctor. The misdiagnose experience had negative impact on the patients' mental state and prognosis[30]. Thus, more detailed evaluation and intervention on the psychological status of STS patients should be made before and after their diagnose.

The relationship between the patients and those around them, especially their families could influence the patients' mental status[31, 32]. Our previously studies found that families of Chinese cancer patients may conceal information related to the patient's treatment, believing it could prevent the pain and distress of the patient[11,33]. In this study, we found that some STS patients also conceal their family members, which indicated physicians should pay more attention to the skills of how to disclose the cancer diagnosis. Previous studies found that adolescent and young patients would like to exchange their experience and cope strategies, thus support each other, and meet each other's psychosocial needs, but sometimes the situation can be challenging when they have to deal with the death of peers[34,35]. In our study, we confirmed these previous discoveries and found that STS patients in their older age would also like to share their experience with each other, but their communications were more focused on sharing of medical information.

We found different attitude toward work in STS patients. Previous study had found that most cancer patients returned to work while STS patients are less likely to return to work because their cancer status blocked the process[36, 37]. Our study found the struggle about whether to return to work and the happiness when STS patients can continue to work. When STS patients get back to their work, they hope to leave the disease behind, which can be 
encouraging[38]. Future research could conduct in-depth discussions on whether patients could return to work, and how to guide them before returning to work.

We explored STS patients' fear and expectation about the future. In traditional Chinese culture, it is taboo and ominous to discuss death and dying in front of people [39]. But in this research, by depicting their future in their writing, some of the patients shared their fears of death. Like other cancer patients[40,41], STS patients felt fear and unsure about their future, they worried about their family, but we also found their strong desire and hopes for the future. Their expectations are simple, like enjoying delicious food, staying with their family and doing something good for society. They also want to return to normal life, which is almost impossible under current treatment mode[42]. Therefore, studies in the future need to focus more on the STS patients' fears and expectations, and carry out targeted interventions to further improve their quality of life and meet their treatment needs.

The pilot qualitative study indicated that expressive writing could be applicable for health care professionals to understand the psychological aspects of patients of rare cancer. Expressive writing is personal and emotional writing without regard to spelling, grammatical or other technical aspects of writing[23]. So we think it is promising to be applied in different types of cancer patients in different cultural settings. It is worth noting that different themes could emerge during the writing process under different culture background. In the current study, emotional expressions were seen more as interactive experiences reflecting the Asian cultures of collectivism and family recognition through achievement.

\section{Strengthens and Limitations}

This research reported some special experience of STS patients which may provide a different insight on how to improve their psychological status and prognosis in the future. The participants in this study were recruited primarily from a single medical center with a limited sample size. Thus, these findings can only reflect part of the experience and feelings. Because of the rarity of STS, we didn't recruit many patients in this qualitative study. But we tried to minimize this by using standard protocols and prolonged writing sessions compared with previous studies. Moreover, the ongoing randomized clinical trial will further examine the effectiveness of expressive writing in STS patients.

\section{Conclusion And Relevance To Clinical Practice}

In conclusion, this qualitative study suggested that expressive writing was acceptable and feasible in Chinese sarcoma patients. It revealed multiple topics including treatment process, interpersonal relationship, coping strategies and views about the future among Chinese STS patients. The different themes revealed the process of acceptance and adaptation to life change. And the different experience and attitude may affect the quality of life in STS patients. It is necessary for doctors and nurses to be aware of the specific psychological status of STS patients, strengthen the diagnosis and treatment of sarcoma and master the skills of communicating with patients and their families. Standard and personalized care should be offered to them in different stages to enhance their psychological health and quality of life.

\section{Declarations}

Acknowledgements

Thanks to the guidance of the Cancer Psychology and Health Management Committee of Sichuan Cancer Society (S.C.S.).

Contribution of the Paper

1. This research is the first qualitive study conducted among soft tissue sarcoma patients in China using expressive writing.

2. This research analyzed and discussed soft tissue sarcoma patients' different experiences and perspectives on topics of treatment process, interpersonal relationship, coping strategies and views about the future.

3. This research recorded unique experience and attitude among soft tissue sarcoma patients using the patient's words and depicted dynamic process of acceptance and adaptation to the cancer among soft tissue sarcoma patients in China.

\section{References}

1. Farid M, Ngeow J. Sarcomas Associated With Genetic Cancer Predisposition Syndromes: A Review. Oncologist. 2016 Aug;21(8):1002-13.

2. Katz D, Palmerini E, Pollack SM. More Than 50 Subtypes of Soft Tissue Sarcoma: Paving the Path for Histology-Driven Treatments. American Society of Clinical Oncology educational book American Society of Clinical Oncology Annual Meeting. 2018 May 23;38:925-38.

3. Kluetz PG, Slagle A, Papadopoulos EJ, Johnson LL, Donoghue M, Kwitkowski VE, et al. Focusing on Core Patient-Reported Outcomes in Cancer Clinical Trials: Symptomatic Adverse Events, Physical Function, and Disease-Related Symptoms. Clin Cancer Res. 2016 Apr 1;22(7):1553-8.

4. Gamboa AC, Gronchi A, Cardona K. Soft-tissue sarcoma in adults: An update on the current state of histiotype-specific management in an era of personalized medicine. CA Cancer J Clin. 2020 May;70(3):200-29.

5. Martins A, Whelan JS, Bennister L, Fern LA, Gerrand C, Onasanya M, et al. Qualitative study exploring patients experiences of being diagnosed and living with primary bone cancer in the UK. BMJ Open. 2019 Sep 24;9(9):e028693.

6. Gerrand C, Furtado S. Issues of Survivorship and Rehabilitation in Soft Tissue Sarcoma. Clin Oncol (R Coll Radiol). 2017 Aug;29(8):538-45. 
7. Kenten C, Ngwenya N, Gibson F, Flatley M, Jones L, Pearce S, et al. Understanding care when cure is not likely for young adults who face cancer: a realist analysis of data from patients, families and healthcare professionals. BMJ Open. 2019 Jan 28;9(1):e024397.

8. Arora NK, Finney Rutten LJ, Gustafson DH, Moser R, Hawkins RP. Perceived helpfulness and impact of social support provided by family, friends, and health care providers to women newly diagnosed with breast cancer. Psychooncology. 2007 May;16(5):474-86.

9. Lee S, Chen L, Ma GX, Fang CY, Oh Y, Scully L. Challenges and Needs of Chinese and Korean American Breast Cancer Survivors: In-Depth Interviews. North American journal of medicine \& science. 2013 Feb 2;6(1):1-8.

10. Wang L, Geng X, Ji L, Lu G, Lu Q. Treatment decision-making, family influences, and cultural influences of Chinese breast cancer survivors: a qualitative study using an expressive writing method. Support Care Cancer. 2019 Nov 18.

11. Yi TW, Deng YT, Chen HP, Zhang J, Liu J, Huang BY, et al. The discordance of information needs between cancer patients and their families in China. Patient Educ Couns. 2016 May;99(5):863-9.

12. Huang B, Chen H, Deng Y, Yi T, Wang Y, Jiang Y. Diagnosis, disease stage, and distress of Chinese cancer patients. Ann Transl Med. 2016 Feb;4(4):73.

13. Pennebaker JW, Beall SK. Confronting a traumatic event: toward an understanding of inhibition and disease. Journal of abnormal psychology. 1986;95(3):274.

14. Pennebaker JW. Expressive Writing in Psychological Science. Perspect Psychol Sci. 2018 Mar;13(2):226-9.

15. Milbury K, Spelman A, Wood C, Matin SF, Tannir N, Jonasch E, et al. Randomized controlled trial of expressive writing for patients with renal cell carcinoma. J Clin Oncol. 2014 Mar 1;32(7):663-70.

16. Lu Q, Gallagher MW, Loh A, Young L. Expressive Writing Intervention Improves Quality of Life Among Chinese-American Breast Cancer Survivors: A Randomized Controlled Trial. Ann Behav Med. 2018 Oct 22;52(11):952-62.

17. Lepore SJ, Revenson TA, Roberts KJ, Pranikoff JR, Davey A. Randomised controlled trial of expressive writing and quality of life in men and women treated for colon or rectal cancer. Psychol Health. 2015;30(3):284-300.

18. Trotter RT, 2nd. Qualitative research sample design and sample size: resolving and unresolved issues and inferential imperatives. Prev Med. 2012 Nov;55(5):398-400.

19. Taylor MF, Pooley JA. Life is precious: Sarcoma/giant-cell tumors survivors' perspectives on their psychological journey. Journal of psychosocial oncology. 2018 Nov-Dec;36(6):681-99.

20. Davidge KM, Eskicioglu C, Lipa J, Ferguson P, Swallow CJ, Wright FC. Qualitative assessment of patient experiences following sacrectomy. J Surg Oncol. 2010 May 1;101(6):447-50.

21. Della CD, Teo DCL, Agiananda F, Nimnuan C. Culturally informed psychotherapy in Asian consultation-liaison psychiatry. Asia Pac Psychiatry. 2021 Mar;13(1):e12431.

22. Ji LL, Lu Q, Wang LJ, Sun XL, Wang HD, Han BX, et al. The benefits of expressive writing among newly diagnosed mainland Chinese breast cancer patients. J Behav Med. 2020 Jun;43(3):468-78.

23. Kupeli N, Chatzitheodorou G, Troop NA, Mclnnerney D, Stone P, Candy B. Expressive writing as a therapeutic intervention for people with advanced disease: a systematic review. BMC Palliat Care. 2019 Aug 2;18(1):65.

24. SohI SJ, Dietrich MS, Wallston KA, Ridner SH. A randomized controlled trial of expressive writing in breast cancer survivors with lymphedema. Psychol Health. 2017 Jul;32(7):826-42.

25. Fern LA, Birch R, Whelan J, Cooke M, Sutton S, Neal RD, et al. Why can't we improve the timeliness of cancer diagnosis in children, teenagers, and young adults? BMJ (Clinical research ed). 2013 Oct 29;347:f6493.

26. McDonough J, Eliott J, Neuhaus S, Reid J, Butow P. Health-related quality of life, psychosocial functioning, and unmet health needs in patients with sarcoma: A systematic review. Psychooncology. 2019 Apr;28(4):653-64.

27. Goedhart LM, Gerbers JG, Ploegmakers JJ, Jutte PC. Delay in Diagnosis and Its Effect on Clinical Outcome in High-grade Sarcoma of Bone: A Referral Oncological Centre Study. Orthop Surg. 2016 May;8(2):122-8.

28. Buvarp Dyrop H, Vedsted P, Rædkjær M, Safwat A, Keller J. Routes to Diagnosis for Suspected Sarcoma: The Impact of Symptoms and Clinical Findings on the Diagnostic Process. Sarcoma. 2016;2016:8639272.

29. Andritsch E, Beishon M, Bielack S, Bonvalot S, Casali P, Crul M, et al. ECCO Essential Requirements for Quality Cancer Care: Soft Tissue Sarcoma in Adults and Bone Sarcoma. A critical review. Critical reviews in oncology/hematology. 2017 Feb;110:94-105.

30. Weaver R, O'Connor M, Carey Smith R, Halkett GK. The complexity of diagnosing sarcoma in a timely manner: perspectives of health professionals, patients, and carers in Australia. BMC Health Serv Res. 2020 Aug 3;20(1):711.

31. Erker C, Yan K, Zhang L, Bingen K, Flynn KE, Panepinto J. Impact of pediatric cancer on family relationships. Cancer Med. 2018 May;7(5):1680-8.

32. Reblin M, Stanley NB, Galligan A, Reed D, Quinn GP. Family dynamics in young adult cancer caregiving: "It should be teamwork". Journal of psychosocial oncology. 2019 Jul-Aug;37(4):526-40.

33. Jiang Y, Liu C, Li JY, Huang MJ, Yao WX, Zhang R, et al. Different attitudes of Chinese patients and their families toward truth telling of different stages of cancer. Psychooncology. 2007 Oct;16(10):928-36.

34. Zebrack B, Isaacson S. Psychosocial care of adolescent and young adult patients with cancer and survivors. J Clin Oncol. 2012 Apr 10;30(11):12216. 
35. Kaluarachchi T, McDonald F, Patterson P, Newton-John TRO. Being a teenager and cancer patient: What do adolescents and young adults with cancer find valuable and challenging with their friends and cancer peers? Journal of psychosocial oncology. 2020 Mar-Apr;38(2):195-209.

36. Leuteritz K, Friedrich M, Sender A, Richter D, Mehnert-Theuerkauf A, Sauter S, et al. Return to Work and Employment Situation of Young Adult Cancer Survivors: Results from the Adolescent and Young Adult-Leipzig Study. Journal of adolescent and young adult oncology. 2020 Aug 3.

37. Main DS, Nowels CT, Cavender TA, Etschmaier M, Steiner JF. A qualitative study of work and work return in cancer survivors. Psychooncology. 2005 Nov;14(11):992-1004.

38. Zambrano SC, Kollár A, Bernhard J. Experiences of return to work after treatment for extremital soft tissue or bone sarcoma: Between distraction and leaving the disease behind. Psychooncology. 2020 Apr;29(4):781-7.

39. Chen Q, Flaherty JH, Guo JH, Zhou Y, Zhang XM, Hu XY. Attitudes of Older Chinese Patients Toward Death and Dying. J Palliat Med. 2017 Dec;20(12):1389-94.

40. Košir U, Denis-Larocque G, Tsimicalis A, Freeman C, Turcotte RE, Cury F, et al. Psychological functioning, coping styles and their relationship to appraisal of physical limitations following invasive surgical procedures for soft-tissue sarcoma: A qualitative study. J Surg Oncol. 2020 Jun;121(8):1266-75.

41. Shaha M, Bauer-Wu S. Early adulthood uprooted: transitoriness in young women with breast cancer. Cancer Nurs. 2009 May-Jun;32(3):246-55.

42. Kain J, Carlson A, Kahler J, Bemboom J, McDonald K, Miller B. Lessons and Advice From Our Patients: A Focus Group of Sarcoma Survivors. Iowa Orthop J. 2017;37:139-46. 